\title{
Happy Birthday!
}

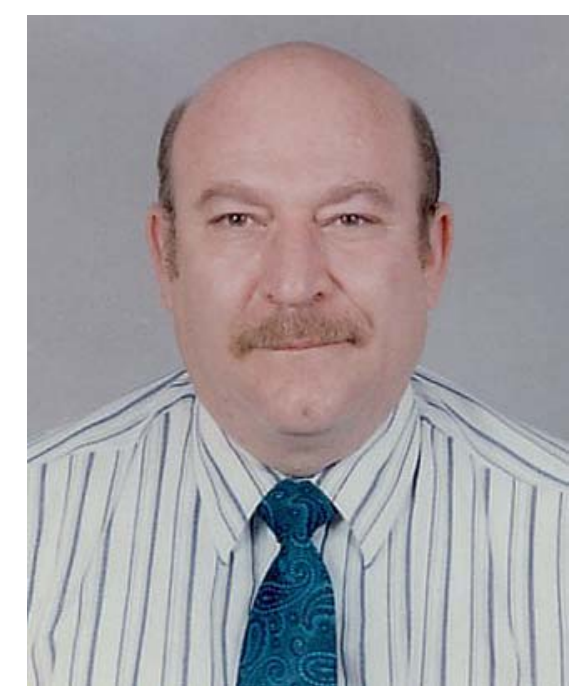

\section{Professor Hassan Y. Aboul-Enein 65th Birthday}

On 12 January 2008, Professor Aboul-Enein will celebrate his 65th Birthday.

Professor Aboul-Enein received his first degree at Cairo University in 1964 and then went on to study in the USA, receiving a PhD in Medicinal Chemistry from the University of Mississippi in 1971. He worked as an Assistant Professor at the University of Alabama in Birmingham and University of Iowa and then in the pharmaceutical industry in the USA. Professor Aboul-Enein moved to Riyadh, Saudi Arabia where he occupied a number of posts at the King Saud University and later at King Faisal Specialist Hospital and Research Centre. After over 30 years in Riyadh, he returned to Egypt in 2006 and is now Professor Emeritus at the National Research Centre in Cairo. He is also a consultant for several academic institutions in Malaysia, China, USA and Egypt. In the course of his long career Professor Aboul-Enein has published over 700 papers on pharmaceutical and biomedical analysis in addition to books and numerous presentations at scientific meetings. He has been a valued member of the Editorial Board of Chromatographia for a long time and we hope that we will be able to retain his services for many years to come.

The publisher, the editors and the readers of CHROMATOGRAPHIA congratulate him on his special day and wish him all the best for the future. 